University of Wollongong

Research Online

SMART Infrastructure Facility - Papers

Faculty of Engineering and Information

Sciences

$1-1-2008$

Safe water for people in low, small Island Pacific Nations: The rural-urban dilemma

Ian White

Tony Falkland

Taboia Metutera

Mourongo Katatia

Tererei Abete-Reema

See next page for additional authors

Follow this and additional works at: https://ro.uow.edu.au/smartpapers

Part of the Engineering Commons, and the Physical Sciences and Mathematics Commons

Research Online is the open access institutional repository for the University of Wollongong. For further information contact the UOW Library: research-pubs@uow.edu.au 


\title{
Safe water for people in low, small Island Pacific Nations: The rural-urban dilemma
}

\begin{abstract}
The issue of ensuring that growing communities in small island countries have access to safe water and adequate sanitation is examined in Kiribati, whose islands are spread over three million square kilometres in the central Pacific. Its coral island communities have water supply and sanitation problems among the most difficult in the world. Formulaic developed-world approaches, models, techniques and toolboxes that do not consider the social and cultural context have had little success. Changes in approach at the international, national and local levels are called for, and the resourcing of village-level water and sanitation committees would return ownership and control in rural communities to its traditional base.
\end{abstract}

\section{Keywords}

nations, rural, urban, small, safe, low, people, dilemma, pacific, island, water

Disciplines

Engineering | Physical Sciences and Mathematics

\section{Publication Details}

White, I., Falkland, T., Metutera, T., Katatia, M., Abete-Reema, T., Overmars, M., Perez, P. \& Dray, A. (2008). Safe water for people in low, small Island Pacific Nations: The rural-urban dilemma. Development (Cambridge), 51 (2), 282-287.

\section{Authors}

Ian White, Tony Falkland, Taboia Metutera, Mourongo Katatia, Tererei Abete-Reema, Marc Overmars, Pascal Perez, and Anne Dray 


\section{Local/Global Encounters}

\section{Safe Water for People in Low, Small Island Pacific Nations: The rural-urban dilemma}

IAN WHITE, TONY

FALKLAND, TABOIA

METUTERA,

MOURONGO

KATATIA, TEREREI

ABETE-REEMA,

MARC OVERMARS,

PASCAL PEREZ AND

ANNE DRAY

\begin{abstract}
The issue of ensuring that growing communities in small island countries have access to safe water and adequate sanitation is examined in Kiribati, whose islands are spread over three million square kilometres in the central Pacific. Its coral island communities have water supply and sanitation problems among the most difficult in the world. Formulaic developed-world approaches, models, techniques and toolboxes that do not consider the social and cultural context have had little success. Changes in approach at the international, national and local levels are called for, and the resourcing of village-level water and sanitation committees would return ownership and control in rural communities to its traditional base.
\end{abstract}

KEYWORDS low coral islands; water supply; sanitation; urban-rural divide

\section{Introduction: The great commission}

The UN General Assembly, in its Millennium Declaration in 2000, resolved 'to halve by the year 2015 the proportion of the world's population who are unable to reach or afford safe drinking water' and 'to stop the unsustainable exploitation of water resources'. The World Summit on Sustainable Development in Johannesburg in 2002 also set a new target of 'halving the proportion of people who do not have access to basic sanitation by 2015'. These global goals are the greatest international challenges in the water and sanitation sector.

In the developed world there has been an implicit, and in some cases explicit, assumption that meeting these goals is relatively straightforward, requiring merely the transfer of tools, models, concepts and techniques from developed to developing countries. This has spawned a plethora of generic decision support systems, models and toolboxes to assist in this transfer (Global Water Partnership, 2003). This assumption and approach fails to appreciate the cultural, social, environmental complexities, constraints and resource limitations faced in many developing countries. We illustrate the complexities by examining urban and rural water supply and sanitation issues in the central Pacific small island nation, the Republic of Kiribati.

Development (2008) 51, 282-287. doi:10.1057/dev.2008.18 


\section{White et al: Safe Water in Small Island States}

\section{Water in small island nations}

The Barbados Conference on the Sustainable Development of Small Island States in 1994 helped raise awareness of their fragility and vulnerability. This vulnerability arises from their remoteness, small land area, rapid population growth, restricted capacity and resources, and sensitivity to climate variability (Talu et al., 1979). Low Gross Domestic Product, limited trading opportunities and increasing urbanization are straining traditional support mechanisms (Ward, 1999) and customary approaches to hazard reduction.

Many small islands in the Pacific, Indian and Atlantic Oceans have maximum widths less than $3 \mathrm{~km}$. In these very small islands, surface water resources are almost non-existent because the soils are coarse coral sands. Fresh groundwater resources often exist as shallow, thin veneers of freshwater floating over seawater (Underwood et al., 1992). Urban and peri-urban low coral atoll communities face water problems that are among the most critical in the world (Carpenter et al.,
2002). Expanding human settlements and increasing demand, agricultural activities and waste disposal, frequent droughts, climate variability and seawater inundation during storms and sea level rise as well as conflicts between traditional subsistence resource rights and the demands of urbanized societies are some of the difficulties (White et al., 1999; Falkland, 2002). Urban atoll communities have the potential to rapidly pollute groundwater with human and animal wastes so that water-borne diseases are often endemic, and infant death rates due to water-borne diseases are tragically high.

\section{Water resources, supplies and sanitation in the Republic of Kiribati}

The Republic of Kiribati has 32 atolls and one raised island spread over three island groups (Gilberts, Line and Phoenix Islands) and across three million square kilometres of the central Pacific (see Figure 1). Over 43 percent of its

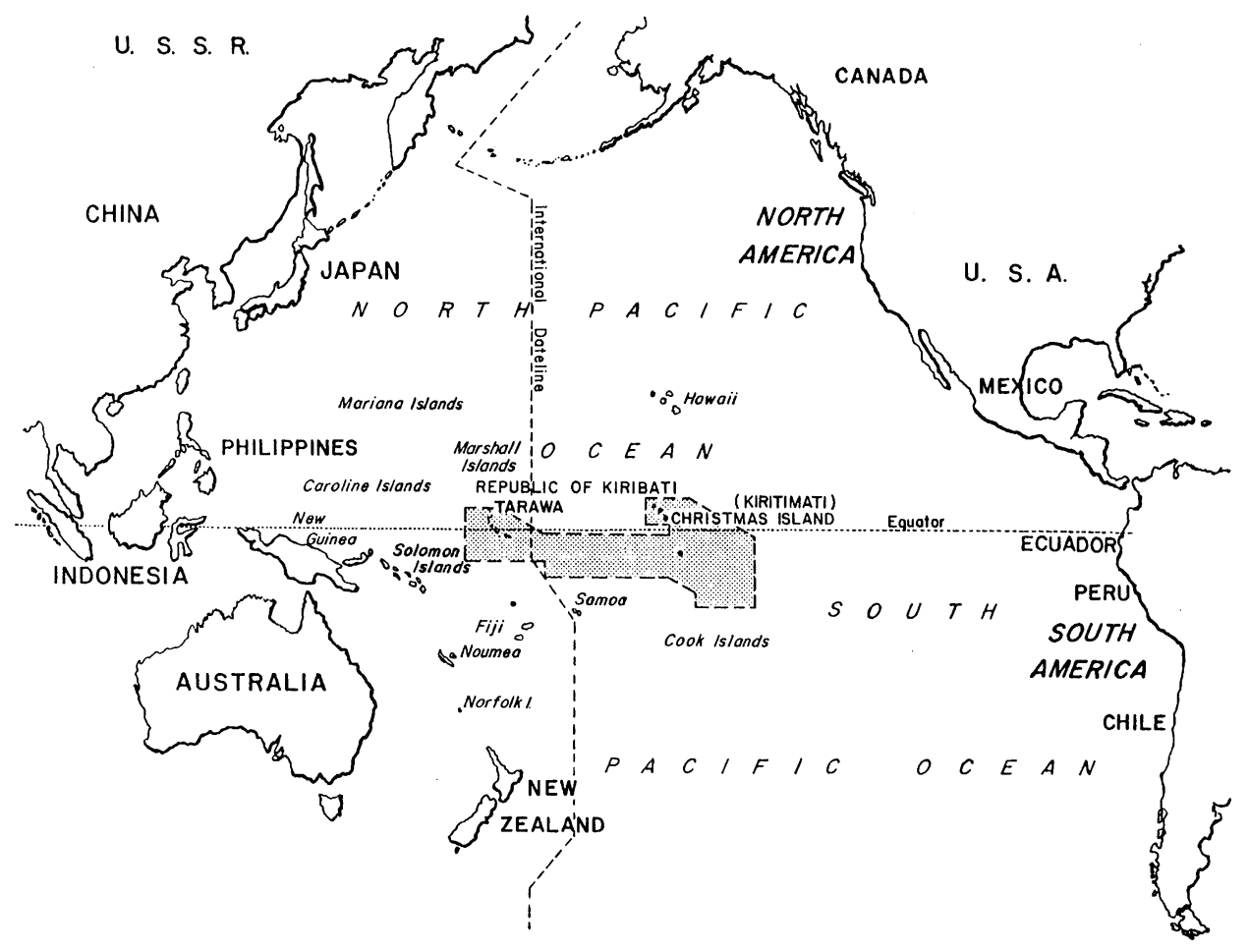

Figure 1: Location of the Republic of Kiribati in the central western Pacific. 


\section{Development 51(2): Local/Global Encounters}

population is crowded into one urban centre, South Tarawa, with population densities as high as 15,000 people per square kilometre. Settlement on groundwater source areas has led to their abandonment as sources for urban water supply. The remainder of the population are scattered over 167 villages in 22 atolls and islands. A recent national consultation undertaken as part of the Kiribati Adaptation to Climate Change Programme showed that most of I-Kiribati has overwhelming concerns about freshwater (World Bank, 2006). Seven out of the top ten communityidentified adaptation strategies were directly water-related, focusing on the supply of adequate quantities of safe freshwater and protecting water sources.

In terms of the Environmental Vulnerability Index, Kiribati is in the top 10 percent of most vulnerable nations in the world (Kaly et al., 2003). The incidences of illnesses and deaths from water-borne diseases are among the highest in the Pacific, and urban areas have higher rates than rural and outer island locations. Limited land areas in small islands in Kiribati also restrict freshwater quantities and storage options, which are especially vulnerable during frequent El Niño-Southern Oscillation-related droughts when stored rainwater is quickly exhausted.

Demand for freshwater in Kiribati is increasing due to population growth and urbanization, both of which in turn impact directly on water quality because of the limited land area for development. Water use for traditional crops such as coconuts, pandanus and taro often competes with water supplies for communities and the fertilization of crops, and the raising of domestic animals, particularly pigs, contributes to groundwater pollution. Human and financial resources are very limited, with estimated per capita GDP around US\$ 1,200 , and the problem of equitably treating both urban and often small, numerous and widely dispersed rural settlements is complex and difficult, particularly because the quantity and quality of outer island groundwaters are unknown except in Kiritimati in the Line Islands.

Sanitation also poses significant problems. In 284 many atolls there is insufficient freshwater for freshwater-flushed sewage systems. The alternatives, pit latrines and septic systems, have very high potential to pollute shallow domestic water wells on which communities depend. Composting toilets is shunned by most I-Kiribati and particularly Ministries as being culturally inappropriate. Many prefer to resort to the traditional method of using the beach, where the tide removes waste, or the bush. Although adequate for low-density populations in outer islands, this poses additional health hazards in higher density urban areas.

Problems in the water and sanitation sector span the responsibilities of many Ministries, which, however, tend to operate as independent 'silos'. Critical issues identified include (White, 2007):

- the high rate of preventable deaths and illnesses caused by water-borne diseases;

- fragmented control, management and protection of freshwater resources;

- financially unsustainable water supply systems;

- growing and sometimes conflicting demands for safe freshwater;

- contamination of fresh groundwater supplies by settlements and sanitation systems;

- impacts of climate change on availability of fresh water;

- inadequate knowledge and monitoring of the nation's freshwater resources;

- decrease in the number of trained water and sanitation specialists and technicians;

- limited use of rainwater storage;

- constraints on development due to limited water supplies;

- limited community participation in freshwater management, protection and conservation;

- limited community understanding of responsible water use and protection;

- difficulties over the declaration of water reserves on private land;

- difficulties in providing services to small villages that are highly dispersed across the Pacific;

- inequities in the provision of services to rural and urban communities;

- lack of clear, unified policy direction, underpinning legislation and plans. 


\section{White et al: Safe Water in Small Island States}

\section{Social and cultural context}

Before European colonialization, the main social group in Kiribati was the kaianga, a group of extended families sharing a piece of land. This social organization remains fundamentally important, particularly in rural, outer island areas. In the southern, drier Gilberts, the traditional form of government was through gatherings of the unemwane (old men) representatives of kaianga, meeting in the maneeaba (meeting house) to reach consensus about issues affecting their island or group of islands. In the wetter North, chiefs ruled over collections of kaianga (Talu et al., 1979). Post-colonial government Ministries have tended to be centralist, based in urban South Tarawa and most have not used kaianga or their village equivalent as a programme delivery mechanism.

Land ownership was and is of absolutely fundamental importance to I-Kiribati. It is the principal form of wealth and carries with it subsistence rights and social, political and legal significance. I-Kiribati cannot be considered poor because almost everyone has access to land ownership. Land in all islands except the growth centre of Kiritimati is privately owned. It entails traditional resource rights, including ownership of groundwater, which is essential for survival, even in urban areas. The developed world notion of water as a commodity is totally foreign to I-Kiribati who have always recognized freshwater as a precious resource. The frequency of droughts and the scarcity of freshwater meant that water, traditionally the responsibility of the kaianga, was used carefully (Talu et al., 1979). Demand management through pricing for Government-reticulated water cuts across traditional practice. It is also easy to appreciate why draft national water resources legislation, which ascribes ownership of reticulated water to the Government, remains to be enacted after 14 years.

There are other cultural influences in small island nations that have a direct bearing on water management. At their heart, however, is the conflict between the demands of a growing, highly urbanized society and the long-established traditions and practices of subsistence communities (Jones, 1997; White et al., 1999). In urban areas, in order to protect fresh groundwater sources, the Government has declared privately owned lands overlying groundwater sources to be Water Reserves. This prohibits settlement and allows eviction of existing dwellers and land-owners from the Reserves, following the payment of compensation or land lease rents. The declaration of Water Reserves is highly contentious, and water ownership remains a sensitive issue with local communities sometimes vandalizing water infrastructure such as groundwater pumps. In addition, with exorable population growth, encroachment of settlers on Reserves continues and has led to the abandonment of some water reserves in South Tarawa. In order to satisfy growing urban needs in South Tarawa, both the government and donors are looking to groundwater sources in North Tarawa. It appears that the lessons learnt in South Tarawa (White et al., 1999) have not been used in negotiation with land-owners in North Tarawa (Dray et al., 2007).

Family obligations are paramount to I-Kiribati. The first obligation is to provide for the extended family. This is evident in the way households tamper with the water reticulation system so that supplies and pressure downgradient are reduced. Although some village structure still exists in South Tarawa, urbanization and squatting have seen a breakdown in traditional village authority, which potentially might have constrained more extreme non-social behaviour in using reticulated water. Family obligations also mean that it is normally not possible for a household to discourage relatives from outer islands squatting on their land in South Tarawa.

Over the past 30 years, aid projects worth tens of millions of dollars have attempted to address the major water supply and sanitation issues in Kiribati. With a few exceptions, these have been short term and narrowly focused and have had limited impact. Indeed, some have been driven by international agendas rather than local priorities and needs.

Following a major diarrhoeal outbreak in children in South Tarawa and the breakdown of communal toilets, the Government of Kiribati requested Australian assistance in upgrading the sanitation and water supply systems in 1993. 


\section{Development 51(2): Local/Global Encounters}

The Australian International Development Assistance Bureau's Pacific Regional Team conducted a field appraisal (AIDAB, 1993). It concluded that the problem in South Tarawa was critical and should be addressed in as comprehensive a manner as possible if sustainable and effective development is to be achieved. It recommended a multi-disciplinary, coordinated, long-term (at least ten years) programme with multiple components in community health, education, water supply, sanitation, appropriate technology, institutional strengthening and management being conducted in parallel rather than through individual components and with annual budgets of several million (1990) dollars. This recommendation, which recognized the long-term engagement necessary, was alas ignored.

\section{Future options}

To tackle the water and sanitation issues discussed above, strategies are needed at the international, national and local levels that recognize the social and cultural context and the complexity of the issues. Because of the limited financial and human resources, Kiribati has relied on international aid and donor agencies to assist in addressing water and sanitation problems. These aid and donor programmes in the water and sanitation sector have tended to be relatively short term and narrowly focused, particularly on the water and sanitation infrastructure needs and on the agendas of international agencies. Although community awareness has been raised in some of these projects, the time required to achieve both trust and behavioural change has not been generally appreciated. Community participation in the planning, design and management of water and sanitation development has been minimal and is not encouraged by government Ministries. Donor and aid programmes that are sensitive to cultural issues, recognize local priorities, value effective community participation and appreciate the long time-scale for behavioural change are more likely to be successful.

At the national level, there is an opportunity for the Government, whose basic principles include equity, to provide leadership and direction. National water policy, legislation and plans focusing on the provision and protection of sustainable and safe water supplies and appropriate sanitation systems are needed to provide direction and coherence to Ministries with responsibility in water and to support the groundswell of public demand. Many of the pressing problems can be addressed through five policy objectives (White, 2007):

- improve understanding and monitoring of water resources and their use;

- increase access to safe and reliable water supplies and appropriate sanitation;

- achieve financially, socially and environmentally sustainable water resource management;

- increase community participation in water management and conservation; and

- improve governance in the water and sanitation sector.

The participation of non-government organizations and community groups with the water and sanitation Ministries in a national water and sanitation coordination committee is essential to oversee, implement and monitor the outcomes of government policy. The fundamental differences between urban and rural outer island situations need to be explicitly recognized and addressed; 'one-size' does not fit all. Most importantly, village-level water and sanitation committees, nurtured and resourced under island councils, would recognize the cultural context and help return control of the protection and management of water resources to the local level in rural and outer island areas.

\section{Acknowledgements}

This work was initiated under the UNESCO IHP V Theme 6, Humid Tropics Programme. It has been supported by UNESCO IHP, the Australian Centre for International Agricultural Research under grant LW1/2001/050, the European Union-SOPAC Pacific Water Governance Project, the Kiribati Adaptation 286 Programme Phase II and the Agence Francaise de Developpement (AFD), France. 


\section{White et al: Safe Water in Small Island States}

\section{References}

AIDAB (1993) 'Field Appraisal, Kiribati - South Tarawa Sanitation and Project Request', Pacific Regional Team, Centre for Pacific Development and Training, June 1993. Unpublished report, Canberra: Australian International Development Assistance Bureau.

Carpenter, Clive, Jeffry Stubbs and Marc Overmars (eds.) (2002) 'Proceedings of the Pacific Regional Consultation on Water in Small Island Countries', Sigatoka, Fiji Islands, 29 July-3 August 2002, Asian Development Bank and South Pacific Applied Geoscience Council, Suva, Fiji.

Dray, Anne, Pascal Perez, Christophe LePage, Patrick D’Aquino and Ian White (2007) 'Who Wants to Terminate the Game? The Role of Vested Interests and Meta-players in the AtollGame Experience', Simulation and Gaming, doi:10.1177/1046878107300673.

Falkland, Anthony (2002) 'Tropical Island Hydrology and Water Resources: Current knowledge and future needs', Hydrology and Water Resources Management in the Humid Tropics. Proceedings of the Second International Colloquium Panama2, Republic of Panama, 22-26 March 1992, UNESCO-IHP-V Paris Technical Documents in Hydrology, No. 52.

Global Water Partnership (2003) Sharing Knowledge for Equitable, Efficient and Sustainable Water Resources Management. ToolBox Integrated Water Resources Management, Version 2. Sweden: GWP, 155pp.

Jones, Paul (1997) 'The Impact of the Socio-Cultural Order on Urban Management in the Pacific: A Case Study of South Tarawa, Republic of Kiribati', PhD thesis, University of Queensland.

Kaly, Ursula, Craig R. Pratt, Jonathan Mitchell and Russell Howorth (2003) 'The Demonstration, Environmental Vulnerability Index (EVI)', SOPAC Technical Report 356, SOPAC, Suva, Fiji, 137pp.

Talu, Alaima, Mikaere Baraniko, Keina Bate, Meita Beiabure, Kunei M. Etekiera, Ueantabo Fakaofo, Maunaa R. Itaia, Bureieta Karaiti, Moarerei T. Kirion, Biritaki Mamara, Ahling Onorio, Betty Schutz, Tangitang Taam, Nakibae Tabokai, Abureti Takaio, Arobati Tautua, Baie Teanako, Rumaroti Tenten, Francis Tekonnang, Tetika Teraku, Tebouaki Tewei, Tebaubwebwe Tiata, Uriam Timiti, Sister Tiura Kaiuea and Kumon Uriam (1979) Kiribati: Aspects of History, Suva, Fiji Islands: Fiji Times and Herald Ltd. 212pp.

Underwood, Mark.R., Frank L. Peterson and Clifford I. Voss (1992) 'Groundwater lens dynamics of coral atolls', Water Resources Research 28: 2889-902.

Ward, R.Gerard (1999) WideningWorlds, ShrinkingWorlds, the Reshaping of Oceania. Pacific Distinguished Lecture 1999. Canberra: Centre for the Contemporary Pacific, Australian National University.

White, Ian, Anthony Falkland, L. Crennan, Paul Jones, B. Etuati, Eita Metai and Taboia Metutera (1999) 'Issues, Traditions and Conflicts in Groundwater Use and Management', UNESCO-International Hydrological Programme, Humid Tropics Programme. IHP-V Theme 6. Technical Documents in Hydrology No. 25. UNESCO, Paris, 37pp.

White, Ian (2007) 'Water for Healthy Communities, Environments and Sustainable Development: Draft National Water Resources Policy', KAPII Office, Office Te Beretitenti, Government of Kiribati (September 2007).

World Bank (2006) 'Project Document on a Proposed Grant from the Global Environment Facility Trust Fund in the Amount of \$US1.80 Million to the Republic of Kiribati for a Kiribati Adaptation Project - Implementation Phase (KAPII)', unpublished report, Washington DC, USA: World Bank (May 2006). 